\title{
Dionisia García, Correo interior, Sevilla, Renacimiento, 2009, 174 pp.
}

Correo Interior, libro de memoria y testimonio, escrito por Dionisia García, inicia una búsqueda que, una vez comenzada, ya no podrá abandonar. Mi acercamiento a esta obra, quiero hacerlo desde lo que soy: una lectora. Al decir esto, no puedo olvidar a la magnífica excéntrica Helene Hanff en su obra 84, Charing Cross Road, en la que nos seduce porque describe la emoción de la lectura y nos confiesa, esta lectora empedernida, que jamás ha conseguido interesarse por cosas que nunca les hubieran sucedido realmente a las personas. Pero, ¿es posible esta diferenciación?

En palabras "A los lectores", Dionisia declara que trata de manifestar la visión y entendimiento de unos aconteceres vividos o soñados, y lo justifica como autobiografía novelada. No puede ser de otra manera, pues aventurarse en esos aconteceres es adentrarse en un tiempo que ya pertenece a todos y la veracidad de lo contado ya no importa, sólo la verdad de lo recordado o ¿soñado?

La memoria persigue a los hombres, aunque a veces también los abandona. Somos tiempo, nos decía Machado, y con igual temblor que nuestro poeta y dubitativa decisión, Dionisia se adentra en él. Se ayudará de un correo interior, pues la memoria está hecha de nuestra más secreta y personal mirada. Nos construye y sostiene, y es como un misterioso entramado que siempre espera ser desvelado.

Nos introduce en Alendero, pueblo de La Mancha baja, y en una atmósfera en la que desde el comienzo la muerte está presente, no sólo por la orfandad de Alejandra, la niña protagonista, y la muerte de sus dos hermanos mayores, sino como paisaje en su propio hogar. La tinaja en la que se guarda el aceite contiene algo más: “La historia de las lágrimas", un amor imposible entre una joven y un muchacho que no conocía las lágrimas, lo que suponía que no se le considerara humano. La joven llorará por los dos y acabará con su vida en un mar de aceite, y así permanecerá en la intrahistoria de la casa.

Con una prosa limpia y sin concesiones, como la mejor poesía, iremos sabiendo de los trabajos y los días de este pueblo. Marcado por la luna y sus ciclos, como causante de las buenas o malas venturas, y por las estaciones y los atardeceres. Será en la calle de Méndez Núñez, por la que fluirá la existencia a manera de río, en cuyo seno y orillas, se agitará la vida de los hombres.

El relato tiene un tempo lento clásico con picos dramáticos, que en algunos personajes adquiere un tono verdaderamente trágico: no puedo olvidar a la oronda doña Sofía y sus frases hechas, para distinguirse de los demás, y el sonido de su collar de cascabeles que siempre la precedía. Su terrible final, sintetizado en un gemido que miraba con espanto, nos quedará para siempre.

Desde la primera secuencia sabremos de las personas que rodean a Alejandra: su padre, al que con unos pocos trazos conoceremos; Genoveva, la prima, y abuela Teresa, que ocupa toda la escena y es la mujer sabia y culta, aunque sea analfabeta, en la que se sustenta la vida de 
estos huérfanos de mujer, madre y marido.

Ausencias que en Alendero se convierten en eterna presencia y que el luto ayudará a preservar en el recuerdo, sin olvidar a los aparecidos o a los resucitados que, si vuelven, no tendrán sitio en la vida, pues ya pertenecen a la memoria colectiva.

Alejandra, en una casa que está al mismo nivel de la calle, oirá a madres que llaman a sus hijos con gritos agudos y el nombre dentro. Verá, como si estuviese en el cine de su tío Arellano, transcurrir la vida, aunque su perspectiva preferida sea la ventana que fragmenta la realidad y la mantiene a salvo. Así, en medio de una gran nevada y en el silencio más profundo de la naturaleza, verá pasar por la calle, como un cuadro expresionista, un bulto negro que lleva sobre sus espaldas un haz de leña que se derrumba sobre la tierra, y delante un hombre sobre una bestia que resbala en la nieve. Éste gritará por igual al animal y al bulto, su mujer. A los pocos días, sabremos que el bulto-mujer abandona para siempre Alendero, en un anónimo entierro como su triste vida, al igual que el amargo final del desconocido para todos en el pueblo y sus terribles ojos abiertos.

No sólo el oído y la vista ayudarán a Alejandra en la lectura de la vida, sino también el sentido del olfato. Nos lo hará sentir desde la emoción al recrear sus estancias en el huerto de sus abuelos maternos o en la aldea de sus tíos. Con emoción, porque sabe que su Arcadia ya no existe, ni quienes la hicieron posible.

Pero la naturaleza no daba siempre sus dones a los habitantes de este pueblo, en el que las rocas configuran las calles, ya que con cierta regularidad se mostraba ingrata con lluvias torrenciales que arrastraban a los hombres o rayos que los fulminaban. Imprescindibles en su labor de todos los días eran los animales, y sus vidas se entremezclaban en una simbiosis necesaria.

Los cortadores de leña, los buscadores de agua, el herrero, los segadores, las espigadoras... eran trabajos señalados por el buen hacer, pero simplemente transcurrían como los días y su pasar... No así para Alejandra, que con su visión onírica, los engrandece y eterniza. Quiero recordar a Indalencio, un leñador, marcado por la terrible maldición de su madre, ¡maldito!, al matar a su hermano pequeño cuando manipulaba un arma de fuego. Quedó, tras el terrible suceso, sin habla, y su madre enloqueció. El padre velará por él y cuando ocasionalmente lo descubre abrazado a un árbol en contenido llanto, el relato nos dice: "el padre lo atrajo en un abrazo silencioso". No existen mejores palabras para explicar este momento.

Algunos habitantes de Alendero emigraban tratando de buscar mejores medios de vida y este es el caso de un ahijado de abuela Teresa. Cuando va a despedirse, la ocasión dará lugar a uno de los momentos más interesante y cómico de Correo Interior. Las palabras que se cruzan entre los dos y la ventana como frontera, podría ser un diálogo cervantino. El lugar al que va el sobrino aparece en el mapa que muestra a abuela Teresa, pero al preguntarle ella dónde se encuentra Alendero, el sobrino le contesta que no está y, ante tal provocación, la abuela exclama: "QQue me digan a mí que no existe Alendero!", y digo yo: o que me lo digan a mí... que soy su lectora, o como les pasó a los Duques, personajes y lectores del Quijote, que yendo de caza ven, a lo lejos en el camino, a los protagonistas de su novela favorita, D. Quijote y Sancho, y entre la perplejidad y el entusiasmo deciden invitarlos a su palacio a pasar unos días. 
Es como nuestro vivir, una fábula dentro de la otra, o un sueño dentro de otro sueño, y así indefinidamente.

Cervantes, como acabamos de ver, no marcaba fronteras, y nos va llevando a un lado y otro del espejo, como si fuese el fluir natural de la vida y el arte. Por eso, cuando Alejandra insiste a su abuela en que le cuente sólo cosas reales, como nuestra Helene Hanff del comienzo, la abuela se mostrará sorprendida, o como la criada Aquilina que al contar historias le gustaba convertirse en personaje de su propia ficción.

En Alendero viven personajes que no puedo dejar de citar pues les debo esos momentos en que la lectura se transforma en soledad gozosa: el primero, Roberto Flores y su existencia marcada por el engaño, la hermosa Trinidad y su misterioso secreto y, por último, la definitiva historia de Salomé y su muerte entre flores marchitas de la rosa del azafrán y todo por un beso...Cuando abuela Teresa avisa a Alejandra de que va llegando el momento de ir dejando los apegos, coincide con la irrupción en el pueblo de las palabras libertad y revolución. La guerra civil provocará sufrimientos y penalidades, en los que se verá envuelta la niña Alejandra, pero la llevará a conocer más la naturaleza de los hombres y su facilidad para rebasar los límites.

Una vez la guerra terminada, aparecerán vencedores y vencidos. La vida de Alejandra cambiará y nuevas costumbres harán su aparición.

Pero aunque Alendero y sus maestros queden atrás, creo que ella no olvidará nunca la lectura en la escuela de Corazón de Amicis, o a su amiga Ana María, que llega de Francia y le pone color al cielo antes de jugar y tiene en su cabeza colores, olores y cantos que hacen hablar a la naturaleza, como nuestro mirar, le explica su abuela. Cuando Alejandra vea por fin el mar, recordará también a su amigo Álvaro, que ante su pregunta: ¿cómo es el mar?, éste le contesta: como el cielo hecho agua y aquí abajo. Creo que Alejandra lo hubiera dicho mejor, porque siempre ha sido poeta y, ya en su niñez, intuía QUE EL MÍO MESTIERE ES ESCRIBIR, pero primero tuvo que aprender a leer y hoy nos regala estas páginas de su lúcida lectura.

Caty García Cerdán 